\title{
AN ANATOMICAL STUDY OF CORONARY ARTERY DOMINANCE IN HUMAN CADAVERIC HEARTS
}

Natasha Gohain ${ }^{1}$, Rubi Saikia ${ }^{2}$

\section{HOW TO CITE THIS ARTICLE:}

Natasha Gohain, Rubi Saikia. "An Anatomical Study of Coronary Artery Dominance in Human Cadaveric Hearts". Journal of Evolution of Medical and Dental Sciences 2015; Vol. 4, Issue 57, July 16; Page: 9897-9902, DOI: $10.14260 /$ jemds/2015/1432

ABSTRACT: CONTEXT: With ever increasing incidence of coronary heart disease, a thorough study of the coronary arteries is the need of time. AIM: The aim of the present study is to evaluate the coronary dominance pattern which will help the cardiac physicians and surgeons for better diagnosis and management of coronary artery disease. MATERIALS AND METHODS: The study undertaken in the Department of Anatomy, Assam Medical College included 75 perinatal and 15 adult cadaveric human hearts which were preserved in 10\% formaldehyde solution after simple dissecting procedure and the dominance was noted. RESULTS: In the present study, out of total of 90 cases the right coronary dominance was found to be present in 58 cases (64.44\%).This included 34(60.71\%) males and $24(70.59 \%)$ females. Total cases of left coronary dominance were found to be $22(24.45 \%)$. Among these, 15(26.79\%) were males and 7(20.59\%) were females. Finally 10(11.11\%) co-dominant cases were found, of which 7 cases $(12.50 \%)$ were males and 3 cases (8.82\%) were females. CONCLUSION: Thus the study revealed that most of the cases were having right coronary predominance.

KEYWORDS: Coronary arteries, Dominance.

INTRODUCTION: Coronary artery disease, with its potential sequelae of angina pectoris and myocardial ischemia is the most common form of acquired heart disease in developed countries but has now gained same importance in developing country like India. ${ }^{1}$ It ranks third in relation of burden of diseases. ${ }^{1}$ In India, coronary artery disease rates have increased during last 30 years, whereas declining trends have been noticed in developed Western countries. ${ }^{2}$ Data from the land mark Framingham Heart Study showed that deaths from coronary heart disease in India rose from 1.17 million in 1990 to 1.59 million in 2000 and is expected to rise to 2.03 million in 2010. Thus coronary artery disease will assume an epidemic proportion by the year 2015 .

A right coronary artery that supplies the major posterior descending branch has been referred to as a dominant right coronary artery. Right coronary dominance is present in majority of people, and in others it is either left coronary dominance or co-dominance. ${ }^{3}$ Left dominance seems to be associated with higher mortality due to acute infarction and a higher incidence of atherosclerosis. ${ }^{4}$

AIMS \& OBJECTIVES: Anomalous origin and distribution patterns of the coronary arteries may result in significant compromise of the blood flow and hearts which exhibit particular coronary artery dominance is considered to be more susceptible to coronary heart disease. With the above background, the present study is undertaken to study the coronary dominance pattern.

MATERIALS \& METHODS: The study was undertaken in the department of Anatomy in collaboration with department of Obstetrics and Gynaecology and Forensic Medicine, Assam Medical College and Hospital, Dibrugarh. 


\section{ORIGINAL ARTICLE}

\section{EXCLUSION CRITERIA:}

\section{Cadavers Excluded from the Present Study are:}

- Perinates less than 28 weeks of gestation.

- Cadavers with gross congenital malformations.

This was a cadaver dissection based study where perinates and adult cadavers were dissected to observe the arterial dominance. Ethical clearance for the study was obtained from the Institutional ethical committee (Human). Perinatal cadavers were obtained from the department of Obstetrics and Gynaecology after taking informed consents from the parents of the deceased. The adult specimens were collected from the bodies provided for dissection to the undergraduate students. Total 90 human hearts of different age groups and of either sex were studied. Of these, 75 were from perinatal age group and 15 were adults with overall male female ratio of 56:34. Cardiac specimens were dissected out from the cadavers after giving two longitudinal incisions in the right and left parasternal region extending up to sternoclavicular joints and joining them with two transverse incisions above and below the suprasternal notch and xiphisternum respectively. Special care was taken to preserve the pericardium and the vessels attached to the heart. The specimens were properly washed and preserved in $10 \%$ formalin for dissection at a convenient time. Both the coronary arteries and their branches were exposed, examined and the data recorded. For contrast, the arteries were painted with red fabric colour and then photographs were taken.

RESULTS \& OBSERVATIONS: In our study right coronary artery dominance was seen in most of the cases irrespective of age and sex with slightly more prevalence in males. (Table 1a, b, c and Figures 2, 3, 4.)

\begin{tabular}{|c|c|c|c|c|c|c|}
\hline \multirow{2}{*}{ DOMINANCE PATTERN } & \multicolumn{2}{|c|}{ MALE } & \multicolumn{2}{c|}{ FEMALE } & \multicolumn{2}{c|}{ TOTAL } \\
\cline { 2 - 7 } & No. & $\mathbf{\%}$ & No. & $\mathbf{\%}$ & No. & $\mathbf{\%}$ \\
\hline Right Coronary Dominance & 28 & 62.22 & 21 & 70.00 & 49 & 65.33 \\
\hline Left Coronary Dominance & 11 & 24.44 & 7 & 23.33 & 18 & 24.00 \\
\hline Co- Dominance & 6 & 13.33 & 2 & 6.67 & 8 & 10.67 \\
\hline Total & $\mathbf{4 5}$ & $\mathbf{1 0 0 . 0}$ & $\mathbf{3 0}$ & $\mathbf{1 0 0 . 0}$ & $\mathbf{7 5}$ & $\mathbf{1 0 0 . 0}$ \\
\hline Table 1a: Showing Dominance Pattern in Perinates
\end{tabular}

\begin{tabular}{|c|c|c|c|c|c|c|}
\hline \multirow{2}{*}{ DOMINANCE PATTERN } & \multicolumn{2}{|c|}{ MALE } & \multicolumn{2}{c|}{ FEMALE } & \multicolumn{2}{c|}{ TOTAL } \\
\cline { 2 - 7 } & No. & $\mathbf{\%}$ & No. & $\mathbf{\%}$ & No. & \% \\
\hline Right Coronary Dominance & 6 & 54.55 & 3 & 75.00 & 9 & 60.00 \\
\hline Left Coronary Dominance & 4 & 36.36 & 0 & 0.00 & 4 & 26.67 \\
\hline Co- Dominance & 1 & 9.09 & 1 & 25.00 & 2 & 13.33 \\
\hline Total & $\mathbf{1 1}$ & $\mathbf{1 0 0 . 0}$ & $\mathbf{4}$ & $\mathbf{1 0 0 . 0}$ & $\mathbf{1 5}$ & $\mathbf{1 0 0 . 0}$ \\
\hline
\end{tabular}

Table 1b: Showing Dominance Pattern in Adults

\begin{tabular}{|c|c|c|c|c|c|c|}
\hline \multirow{2}{*}{ DOMINANCE PATTERN } & \multicolumn{2}{|c|}{ MALE } & \multicolumn{2}{c|}{ FEMALE } & \multicolumn{2}{c|}{ TOTAL } \\
\cline { 2 - 7 } & No. & $\mathbf{\%}$ & No. & $\mathbf{\%}$ & No. & $\mathbf{\%}$ \\
\hline Right Coronary Dominance & 34 & 60.71 & 24 & 70.59 & 58 & 64.44 \\
\hline Left Coronary Dominance & 15 & 26.79 & 7 & 20.59 & 22 & 24.44 \\
\hline Co- Dominance & 7 & 12.50 & 3 & 8.82 & 10 & 11.11 \\
\hline Total & $\mathbf{5 6}$ & $\mathbf{1 0 0 . 0}$ & $\mathbf{3 4}$ & $\mathbf{1 0 0 . 0}$ & $\mathbf{9 0}$ & $\mathbf{1 0 0 . 0}$ \\
\hline
\end{tabular}

Table 1c: Showing Dominance Pattern in Both Perinates \& Adults 


\section{ORIGINAL ARTICLE}
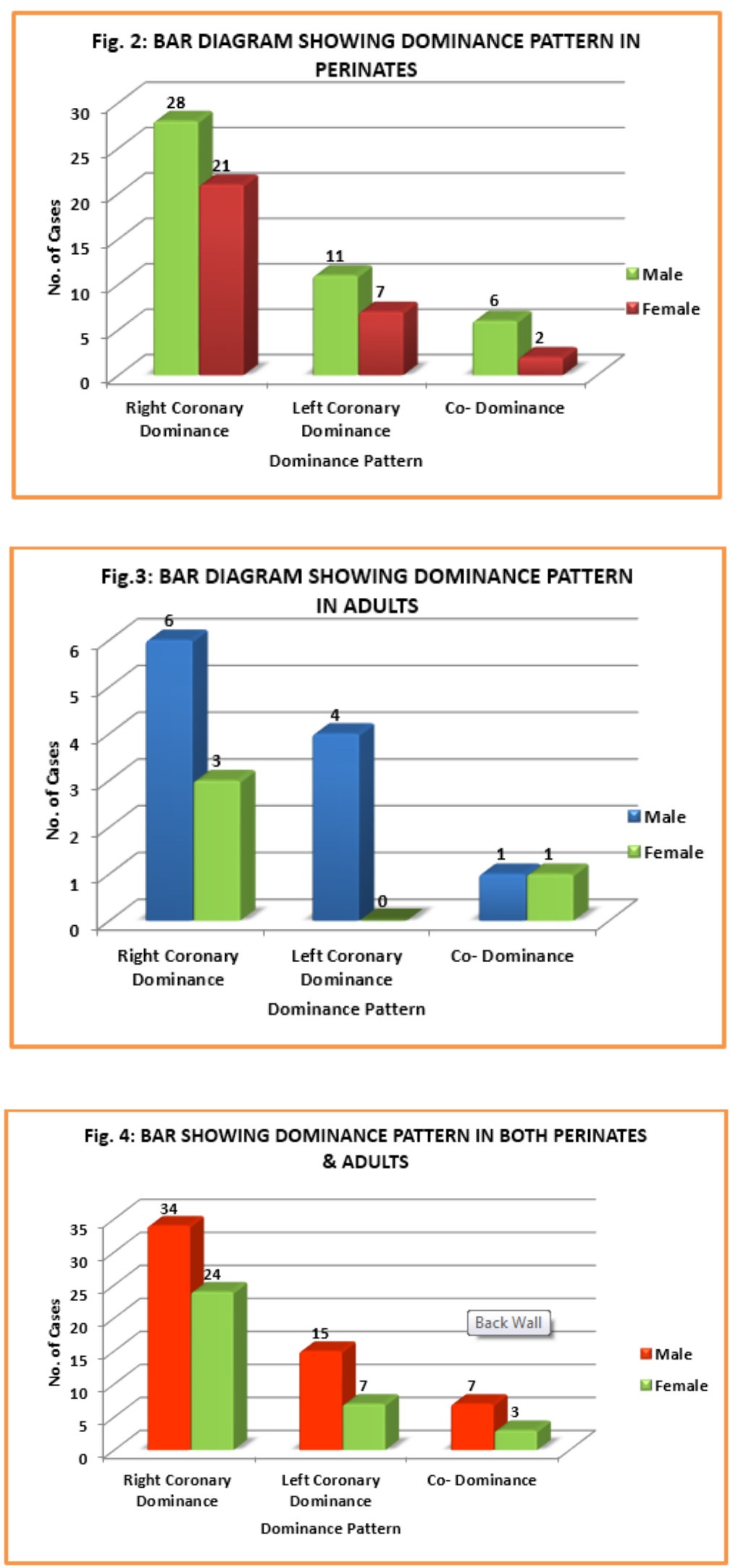


\section{ORIGINAL ARTICLE}

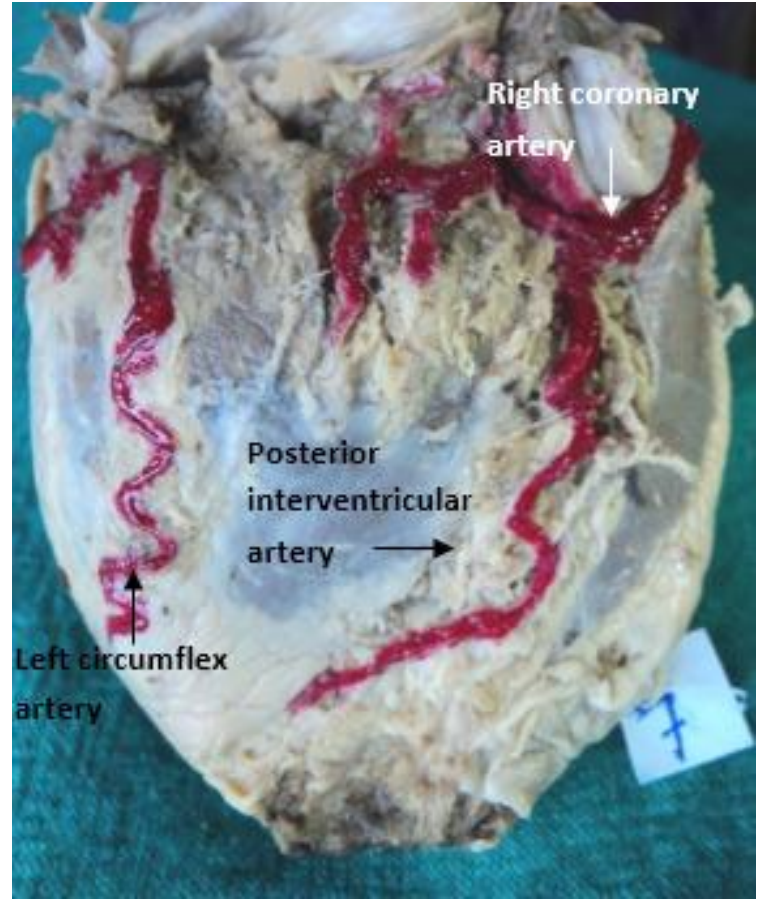

Photograph A: Right coronary artery Dominance (Adult heart, Posterior view)

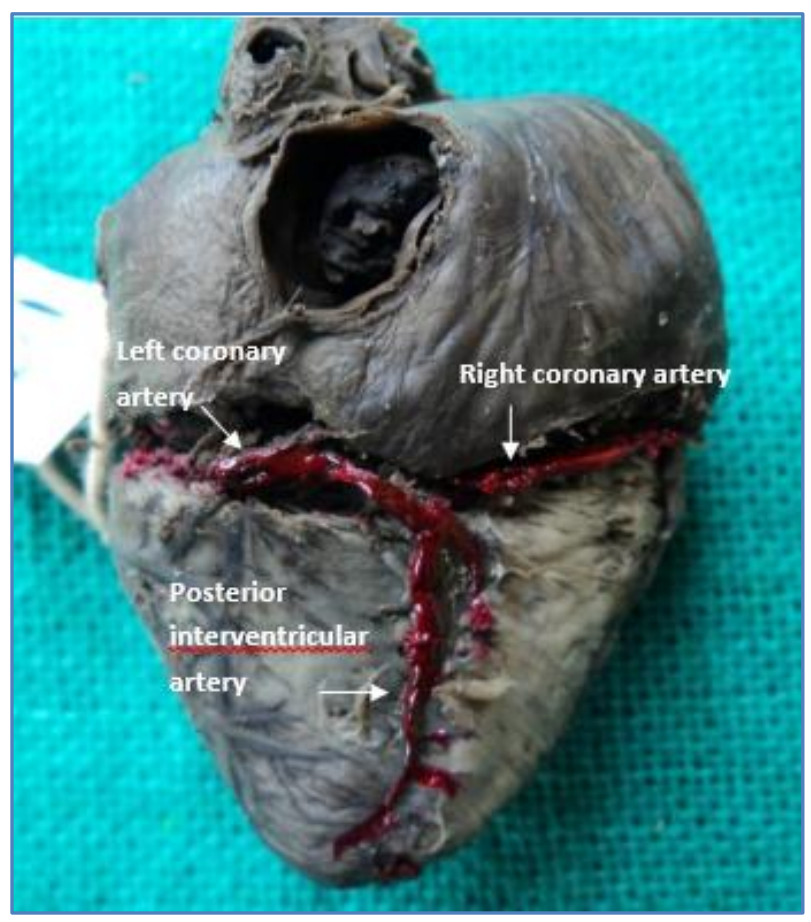

Photograph B: Left coronary artery dominance (Perinatal heart, posterior view)

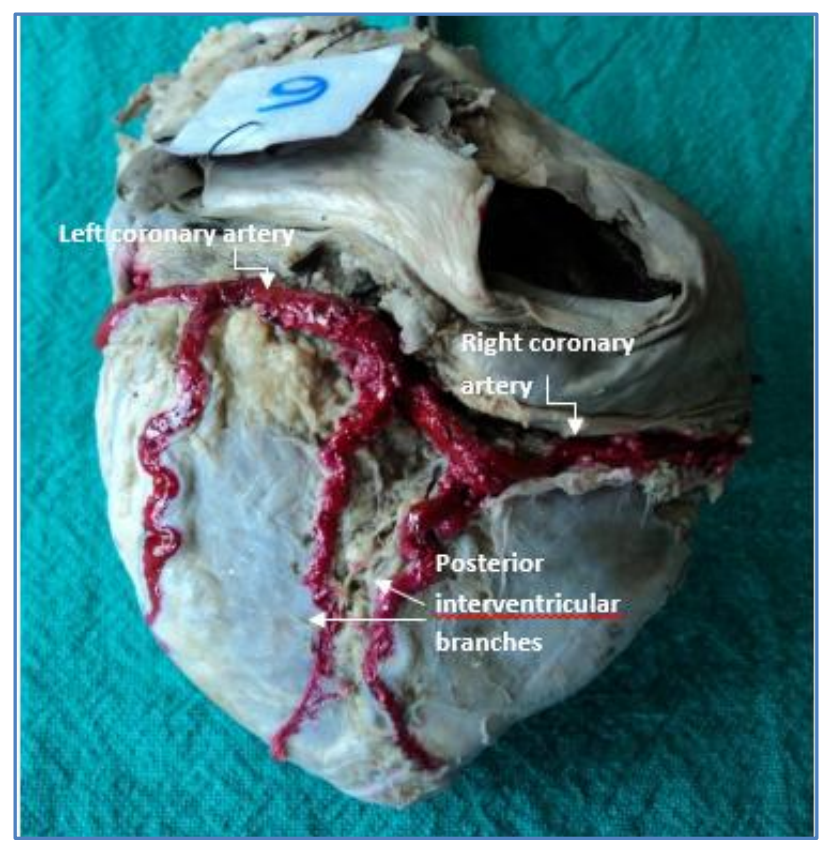

Photograph C: Co-dominance (Adult heart, posterior view)

DISCUSSION: Myocardial infarction has become the major killer for human race in modern times. Social factors, change of food habits and sedentary life style has already increased the load on heart 
muscles and addition of anatomical factors such as dominance pattern of the coronary artery makes the heart more susceptible to ischaemia.2,3,4

Heart gets its blood supply mostly from the coronary arteries. The two major coronary arteries supplying heart are right and left coronary artery. Left coronary artery with its left anterior descending branch and left circumflex branch supplies most of the left ventricle which constitutes the majority of the muscle mass of the heart whereas the right coronary artery with its trunk and posterior descending artery branch supplies major portion of the conducting pathway. ${ }^{5}$

Posterior descending artery branch of the right coronary artery supplies part of the left and right ventricle, posterior portion of inter ventricular septum and AV node. 5 Coronary artery giving posterior descending artery branch is termed as the dominant artery. Eren et $\mathrm{al}^{6}$ in 2008 , Koser et $\mathrm{al}^{7}$ in 2009 and Ozturk et al8 in 2011 have observed the right coronary artery as the most common dominant artery. Prevalence of the right coronary artery dominance was observed to be the most common dominance pattern in the present study a finding similar to others.

Major portion of the myocardium is supplied by left coronary artery and association of left coronary artery with dominance pattern increases the vulnerability of the heart to myocardial ischemia due to increase in muscle mass and area of supply. 3,5

SUMMARY \& CONCLUSION: Dominance can be a significant determinant of prognosis in acquired coronary artery disease. In most individuals with left coronary dominance, the right coronary artery is usually small and often fails to reach the acute (Right) margin of the heart decreasing the potential for rapid development or re-opening of collateral vessels. Thus the knowledge of the morphological variations of the coronary arteries, particularly of coronary dominance, is not only important for management of cardiac trauma but also for prevention of arrhythmia during cardiac surgery resulting from coronary artery occlusion.

\section{REFERENCES:}

1. Braunwald Eugene (1984): Normal coronary anatomy, Heart disease. Brantigan blood supply of the heart. Clinical Anatomy 1963; 373-378.

2. Enas EA, Senthilkumar A (2001). Coronary artery disease in Asian Indians: an update and review. Internet J Cardiol. 2001:1. Accessed 15 Feb. 2005.

3. Datta AK. Essentials of Human Anatomy (Thorax) (2008), 8th Edition. Current Books International. p. 81-85.

4. Fuster V, Alexander R.W, O’Rourke R.A. Hurst's THE HEART (Vol. 1), 10th Edition. International Edition, McGraw-Hill. P 1168-169.

5. Stranding S et al. Grays Anatomy (2005), 40th edition. Churchill Livingstone Elsevier, p. 1017.

6. Eren S, Bayram E, Fil F, Koplay M, Sirvanci M, Duran C, et al (2008). An investigation of the association between coronary artery dominance and coronary variation with coronary arterial disease by multi detector computed tomographic coronary angiography. Journal of Computer Assisted Tomography: Nov/Dec 2008; 32: 929-933.

7. Kosar P, Ergun E, Ozturk C, Kosar U (2009). Anatomic variations and anomalies of the coronary arteries: 64-slice CT angiographic appearance. Diagn Interv Radiol. 2009 Dec; 15(4): 275-83. Epub 2009 Dec. 2.

8. Ozturk et al (2011). Arterial supply of the posterior interventricular sulcus: A CT coronary angiographic study. Surg Radiol Anat.2011 Jan; 33(1): 27-34. 


\section{ORIGINAL ARTICLE}

\section{AUTHORS:}

1. Natasha Gohain

2. Rubi Saikia

\section{PARTICULARS OF CONTRIBUTORS:}

1. Demonstrator, Department of Anatomy, Assam Medical College and Hospital, Dibrugarh, Assam.

2. Associate Professor, Department of Anatomy, Assam Medical College and Hospital, Dibrugarh, Assam.

NAME ADDRESS EMAIL ID OF THE CORRESPONDING AUTHOR:

Dr. Natasha Gohain,

Demonstrator,

Department of Anatomy,

Assam Medical College and Hospital,

Dibrugarh, Assam.

E-mail: drkamal4u@gmail.com

Date of Submission: 04/06/2015. Date of Peer Review: 15/06/2015. Date of Acceptance: 09/07/2015. Date of Publishing: 14/07/2015. 